\title{
THE PSYCHO-SOMATIC SYNDROME OF SPURIOUS PREGNANCY AFTER THE MENOPAUSE
}

\author{
BY \\ BETTY JACOBS \\ Assistant Physician, Royal Edinburgh Hospital for Mental Disorders
}

(RECEIVED 23RD OCTOBER, 1942)

Spurious pregnancy (false pregnancy or pseudocyesis) constitutes a subject of considerable practical importance not only for the general practitioner and obstetrician but also for the psychiatrist, as it presents one of the most impressive examples of the influence of emotional mechanisms on physical processes.

The occurrence of this condition in humans and animals has attracted attention throughout the ages, one of the earliest descriptions being found in the writings of Hippocrates. Paddock, who in 1928 made a survey of the literature on that subject viewed from the obstetric aspect, quotes various authors, among them James Y. Simpson and Montgomery (1863). The psychological significance of the syndrome, however, has not received adequate attention. While some authors maintain that pseudocyesis is found mainly in women of the 25-35 age period, Simpson and Montgomery emphasize its more frequent association with the climacteric period. Paddock maintains that most of the cases reported were young women. He regards false pregnancy at the climacteric as part of the general menopausal syndrome. Maranon (1929) supports Simpson and Montgomery in their view that the frequency of the condition is highest at the climacteric and classifies the condition as a metabolic disturbance originating from emotional causes. "In women whose desire to remain young makes them forget how old they are ... it is striking to note how the suppression of the menses coincides with a general increase in the size of the abdomen." He states that the condition may be due to an unfulfilled desire to have children or to an effort at self-deception that sexual power may not yet be lost. Schwarz (1933) states that pseudocyesis tends to occur mainly in women with a premature menopause. From the psychiatric point of view, Kehrer (1928) has recently surveyed the literature and reported on his own observations. He says that the supposition of pregnancy may be the outstanding delusion in a psychosis and that in many instances mental phenomena may be present in a marked degree even in the absence of bodily changes. The most recent review of the literature has been contributed by Moulton (1942).

Those authors who have stressed the psychopathological implications of the condition have been satisfied in attributing it to wish fulfilment. The discrepancy, however, between the number of cases with a strong desire for pregnancy and those actually presenting signs of pseudocyesis makes it clear that wish fulfilment can result in the production of this particular psycho-somatic syndrome only under certain conditions, still to be defined.

The following case represents a contribution to the understanding of some of those conditions.

Mrs. E. S. aet. 53 was admitted on 24th September 1941. Family history: The mother, to whom the patient was unduly attached, is described as a quiet, sympathetic woman with a deeply religious outlook. She was a midwife of repute. The father, who was 13 years older than his wife, died when the patient was 7 years of age. No nervous or mental illness has been reported in the family. Personal history: The patient was the only child. She describes her early childhood as happy; but she was always solitary and introspective. So strong was her attachment to her mother that she disliked leaving home to go to school. She recalls scenes when she wept at the very thought of leaving her mother and she found it difficult to mix with other children, her contact with her schoolmates being entirely superficial. Occasionally she suffered from "bilious turns," during which she enjoyed a sense of pleasure and satisfaction because she could remain beside her mother and have her special care and attention. She was obsessed with the idea that she was different from her friends and became progressively more dependent on her mother, the only person in whom she could confide and from whom she could derive comfort and encouragement. The menarche occurred at the age of $13 \frac{1}{2}$; menstruation was irregular until the age of 18 when a normal cycle was established. According to herself, she was small and under-developed until the age of 18 , when she began to develop normally and her outlook became less solitary and dependent.

At the age of $19 \frac{1}{2}$ she married, her husband being 12 years older then herself. She says that because of his age she was less afraid of him than of most other men and that he gave her a feeling of protection akin to that which she had come to associate only with her mother. That feeling of dependence remained a prominent feature of her relationship to him. Her attitude towards the physical side of marriage was always immature; she was frigid and constantly harboured a fear of becoming pregnant. This fear was fostered by her mother who thought childbirth undesirable for her daughter because of her delicate childhood. Consequently the patient submitted to intercourse only infrequently, and then only when coitus interruptus was practised. Only in the 13th year of their marriage did normal intercourse take place on a few occasions and it was then that she became pregnant. Even now she complains that her husband took advantage of her and that the pregnancy should never have occurred. Throughout the pregnancy she 
was unhappy and fearful, she had persistent hyperemesis, lost her appetite and on several occasions during the latter 3 months visited her doctor in a state of extreme agitation because she had ceased to feel life. She kept saying that something dreadful was going to happen. Her physical condition was poor at the time of delivery, labour lasted for 2 days and was preceeded by 3 panic attacks, during which she was very agitated and maintained that labour had commenced. Inertia persisted throughout the labour and the patient was quite uncooperative. A forceps delivery was performed and the baby, a girl, was stillborn. The puerperium was characterized by apathy and lack of initiative and her recovery was very gradual. Information received from a friend suggests that she had a melancholic depression at this time. She became more shy and secretive and the doctor advised the husband that the patient should have another child. She became pregnant 2 years later. Though she had the same fears and apprehensions as in the first pregnancy, her physical condition was satisfactory and hyperemesis much less persistent. The labour, like the first, was complicated by inertia but delivery was spontaneous and this child, a boy, was alive. She made a good recovery, took an interest in the child and became very devoted to him. She remained as reticent as ever with strangers, but in the home she was less quiet and secretive. Her whole life had obviously been made much happier by the arrival of the baby. Four years later, however, when her husband developed phthisis, she reverted to her former anxious state with its inhibitions and feelings of inadequacy. After his death 6 months later, she made her home with her mother as she had done before her marriage. She made a good adjustment to this life and was contented and happy until the death of her mother 2 years prior to admission. She became very depressed and felt that a part of herself had died with her mother. She lost all initiative, took no interest in anything, had no appetite, slept badly and could see no hope for her son or herself. While she was in this depressed condition, the incident occurred which, according to her, was responsible for her " pregnancy." In March, 1941, an old schoolfriend, who was in the habit of visiting her home, " ravaged her in her grief." The vague manner in which she recounts the story makes it seem very doubtful whether that incident actually occurred. Previous to the alleged rape, her periods had become very irregular and they ceased altogether thereafter. At that time her depression became more profound and was aggravated still further by the fear of separation from her son who had become eligible for military service. When no further periods occurred, she developed the idea that she was pregnant. She blamed herself for the sin she had committed and contemplated suicide. She rejected all the assurances from her doctor that no pregnancy existed and after a further six weeks she maintained that she felt life. Her depression and agitation became so marked that she had to be admitted to this hospital as a certified patient.

Condition on admission.-The patient was depressed and agitated. Her first question was whether she could be taken to a maternity hospital lest the baby should arrive very soon. She was concerned about whether the necessary facilities for childbirth were available here. Though she expressed the fear that she might die during labour, her main worry seemed to be concerned with what the neighbours at home might say of her. In particular she was worried lest they might believe that her son was the father of the child. She gave a very suggestive history of her symptoms usually associated with pregnancy : morning sickness, frequency, pains in the breasts, discharge from the nipples, quickening at the $14 \mathrm{th}$ week, pain at the small of the back and discomfort when walking. She said that lately her abdomen had been enlarging. . . . She was in a state of utter despair and repeatedly blamed herself for the disgrace she had brought upon herself and her son, saying that if her mother had been alive all this would never have happened. She slept badly, resisted feeding, talked only about her "pregnancy" and kept on asking other patients whether she would be all right.

Physical Examination.-Her abdomen was distended and firm, the swelling reaching the level of the umbilicus. In shape it was broader than that found in pregnancy, no foetal parts could be felt and no foetal heart could be located. She could simulate foetal movements by contracting and relaxing the abdominal muscles. No dullness could be elicited on percussion, the note being hypertympanitic all over, suggesting the condition of meteorism. The breasts were full and enlarged and from the nipple a serous secretion could be expressed. Vaginal examination revealed no evidence of pregnancy. The cervix was elongated and lacerated, the scar causing marked puckering of the edges. There was some laxity of the nelvic floor and the perineum was deficient. The uterus, however, was in good position, quite mobile, and of normal size. The appendages were palpable on both sides and the right ovary was very slightly enlarged. The Aschheim-Zondek Reaction was performed and the result was weakly positive. Two weeks later this was repeated with a negative result.

At first, repeated reassurances that she was not pregnant did not have the slightest effect. She was treated by psychotherapy and although she was very unco-operative in the initial stages, she was later more readily influenced. She began to talk more freely about herself, said she had wanted to have another child, that she had never got over the disappointment of the stillbirth, and that even the birth of her son had not compensated her for the loss of the daughter. About six weeks after admission, she admitted that she was not pregnant, and her depression gave way to a state of comparative contentment. Nevertheless, the physical signs simulating pregnancy persisted : but a week later the abdomen "deflated" overnight, the breast secretion ceased and the AschheimZondek Reaction gave a normal result. During this remission, she was examined by Professor R. W. Johnstone, who recommended that a plastic operation be performed to repair the pelvic floor. This was done on 22 nd December, 1941, with a very good result. She was reassured about her pelvic condition at the time of the operation and she was quite convinced that there had been no pregnancy whatsoever. At the same time, she volunteered the information that her illness might have been due to the great disappointment she had suffered at the time of the stillbirth. She remained well until early March, when she again became depressed, saying that the baby was almost due. This episode, however, lasted for only two weeks and she was readily persuaded that no pregnancy was present. At that time, the delusion was associated with none of the symptoms or physical signs of pregnancy. After two months remission she was found to have hidden a brick and a piece of rope in a cupboard with suicidal intent. Her depression had returned and she was obsessed with the idea that there was a tumour in her abdomen. This delusion soon reverted into the idea of pregnancy and impending labour without any of the previous physical manifestations. The associated depression and agitation had also recurred.

30th September, 1942. The patient has been given a course of electro-convulsant therapy, consisting of seven treatments, during the past three weeks. After the second treatment, she lost the idea of pregnancy, but was still depressed. After the fourth treatment, the depression was replaced by a state of contentment and by the end of the course, the patient had become slightly euphoric. The idea of pregnancy has not recurredApril, 1943. The patient was discharged on 22nd March, 1943. She has completely recovered.

\section{Summary}

This is the case of a widow of 53 who, at the time of the cessation of menstruation, expressed the idea that she was pregnant, attributing conception to an alleged rape. Her general mental condition 
was that of an involutional depression which had been precipitated by the death of her mother and her whole emotional life was centred round the supposed pregnancy. On admission she presented the typical signs of pseudocyesis including positive hormonal reactions. These signs, however, disappeared in the 8th month of the alleged pregnancy and have not recurred. The disappearance of these signs coincided with a complete remission of her mental condition which was, however, only temporary. With a subsequent relapse into her previous depression, the idea of pregnancy recurred. The previous personality was characterised by neurotic trends with features of anxiety and an unduly strong mother fixation which the patient has never been able to resolve. She remained psychosexually immature, was frigid and could never establish a normal relationship to her husband. Her attitude towards her previous pregnancies was that of fear and aversion throughout her reproductive period. Her first pregnancy, occurring 13 years after marriage, resulted in a stillbirth and was followed by an abnormal mental reaction, suggestive of a melancholic depression. Two years later, she gave birth to a normal child. Both pregnancies were complicated by hyperemesis and abnormal anxiety reactions, while both labours were inert. When she was widowed 4 years after the birth of her second child, she returned to her mother's home. The death of her mother 2 years previous to admission was followed by a severe depressive reaction with melancholic features. This depression persisted until the delusion of pregnancy developed. The fear of separation from her son constituted an additional source of apprehension.

\section{Comment}

This patient belongs to the group of cases developing false pregnancy during the climacteric period; the cessation of menstrual functions was certainly one of the precipitating factors in the development of the syndrome. The idea of pregnancy occurred while she was still mourning the loss of her mother and dreading the impending separation from her son. The delusion developed on the background of an involutional depression and her entire emotional life became absorbed in the idea of pregnancy. Her conscious attitude towards that pregnancy was one of fear and guilt, but it was evident that at the same time the pregnancy satisfied a strong subconscious desire. In one of her remissions when she had regained insight, the patient explained her delusion on the basis of a compensation for the disappointment she had suffered by the stillbirth of her first child. It is noteworthy that the attitude of this patient towards pregnancy and childbirth during her active reproductive period had been characterized by aversion and anxiety, and this attitude was obviously responsible for the complications-hyperemesis, false labours, inertia, and puerperal depression. Further, it is not beyond possibility that the inertia, which was of obvious nervous origin, may have contributed to the death of the first child during delivery. The development of a melancholic reaction after the stillbirth is of special interest in view of the results of a recent investigation into the ætiology of such psychoses carried out by the author in this hospital. It has been shown that these conditions tend to be of the depressive type and that strong aversion or ambivalence towards pregnancy can usually be demonstrated. It is probable that the conscious aversion which this patient had shown towards pregnancy in the past originated partly in her neurotic trends resulting in psychosexual immaturity, and partly in the fact that her mother, with whom the patient had identified herself all her life, had discouraged her from having children. This latter circumstance must have had a profound effect on the patient who had never succeeded in resolving her mother fixation. Her whole history bears out the tendency to subordinate herself to her mother, and it is interesting to note that it was not until after the mother's death, which coincided with the end of her own reproductive period, that the imaginary rape occurred. It is likely that her abnormal mother fixation had been responsible for the sexual repression which had characterized her life throughout the active reproductive phase, and that the ideas of rape and pregnancy were the products of a compensatory mechanism. It is characteristic not only of her personality type but also of the depressive condition she presented that she reacted with a strong sense of guilt to those ideas. It is noteworthy that she expressed a fear of being suspected of an incestuous relationship with her son.-The complete psychosomatic syndrome of pseudocyesis presented in this case persisted only for the first 8 months of her illness and thereafter physical signs have been absent even when the idea of pregnancy has recurred. The appearance of those signs can be interpreted as a last effort on the part of the reproductive system while it is still capable of responding to stimulation. From the psychiatric point of view it would not be reasonable to regard the disappearance of those physical signs as the resolution of the condition of spurious pregnancy. It seems appropriate to describe false pregnancy as a psycho-somatic syndrome which may be either complete or merely abortive. In some cases the physical symptoms are of primitive nature only, while the full psychological syndrome is present; in other cases, particularly in younger women, the emphasis is laid on physical signs of the syndrome, while the mental components remain more latent.

The following case shows the typical psychological syndrome of false pregnancy with only abortive physical signs.

Mrs. E. B. aet. 53, admitted on 13th July, 1942. Family history was negative for nervous and mental illness. She had always been well exteriorized and there was nothing unusual in her relationship to her parents. She was married when she was 28 , but she felt no real affection for her husband. She has always been frigid. Of her 4 pregnancies, the first and third resulted in early miscarriages. Her first child died at the age of 3 and the second child, a daughter, is alive and healthy. Her family life was fairly happy until 10 years ago, when she 
felt an increasing aversion to sexual intercourse. Later her husband became an alcoholic and he died from pneumonia in March 1942. During recent years she had become progressively more jealous and suspicious. Her menstrual periods had ceased suddenly at the age of 35 for no known reason (the only abnormality to be found at that time was an extreme retroversion of the uterus). After the death of her husband, her increasing irritability and paranoid attitude towards her environment made her admission to this hospital necessary. When she was examined for certification, she expressed for the first time the belief that she was pregnant.

Condition on admission.- The patient was in a state of mild elation, she was fully orientated and did not mind being brought to hospital. The whole thought content was taken up with her supposed pregnancy. She said that the film star Clark Gable had made her pregnant "through an automatic." She denied having had intercourse with him, said that she had met him before she had met her husband and that he was in love with her but that she was not in love with him, and that she had refused to marry him. Through the same "automatic" she heard the voice of Clark Gable and she maintained that through the medium of this same apparatus she was examined regularly by an eminent obstetrician who came to reassure her about the wellbeing of the baby. She was completely inaccessible to reason, maintaining that she was in the 8th month of her pregnancy and that she could feel life. When it was pointed out that she presented no physical signs of such a condition she demonstrated rhythmic contractions of the abdominal muscles which, according to her, were produced by the movement of the child. Physical examination was completely negative apart from those rhythmic movements described above. The hormonal reactions were negative.

In this case the idea of pregnancy arose on the background of a paranoia developing in the climacteric period. Death of the husband occurring previous to the appearance of that idea may have acted as a precipitating factor. This patient, like the first one reported, had been frigid during the whole of the reproductive period and she, too, had never recovered from the disappointment she had suffered through previous miscarriages. The imaginary pregnancy was attributed to a union with a fantasy hero ; even that delusional sexual relationship was characterized by frigidity and ambivalence. This patient showed no external physical signs, apart from contractions of the abdominal muscles. The lack of response on the part of the generative system may be attributable to the fact that in this case, as distinct from the other, the idea of pregnancy had occurred many years after the unusually early cessation of the ovarian activity; it may also be due to the fact that in this case, the emotional reactions were less profound than in the first and that the patient in her delusions had completely parted from reality ; the character of the psychosis which in this case formed the background of the idea of pregnancy makes it understandable that the delusion did not take possession of the whole of the psycho-somatic personality. However, physical signs were not entirely lacking and the rhythmic movements of the abdominal muscles may be regarded as an abortive expression of the physical part of the syndrome. Such movements were also observed in the first case and both patients denied that they produced them voluntarily. It can be assumed that similar abortive physical signs of the syndrome can be found in the great majority of cases who express the idea of being pregnant after the end of the reproductive period. It is noteworthy that both patients had borne children, but in both cases " obstetric catastrophies" had acted as mental traumata in the past.

The previous history of the second case had again much in common with the histories of women who are apt to develop abnormal mental reactions to real childbirth; the psychosexual make-up of those cases has been described by Zilboorg. This case too, suggests that it would be profitable to study all mental changes with the content of thought centred round reproduction as belonging to one large group as far as the dominant complex is concerned. The psycho-somatic syndrome of spurious pregnancy would be one of that group ; the other conditions to be studied in that context would be neurotic and psychotic reactions during pregnancy, puerperium and lactation ; certain hypochondriacal conditions occurring at the menopause and deriving the content of thought from the same complex would have to be included. It can be assumed that the idea of pregnancy in the climacteric period is, psychogenetically, the antithesis of hypochondriacal ideas associated with that age period and finding expression in complaints of hollowness, emptiness and sometimes amounting to nihilistic ideas. The existence of a psychological relationship between pregnancy and hypochondriacal complaints of this nature is borne out by the observation that such complaints frequently occur in the course of depressive mental changes following childbirth. All mental changes centred round the complex of reproduction have it in common that they are not associated with a specific mental illness, and that they occur on the background of psychoses as well as neuroses.

It is clear that the observations of the two cases presented in this article do not permit of any general conclusions regarding the aetiology of the psychosomatic syndrome of spurious pregnancy. However, it has been possible to demonstrate the complexity of the physiological [and psychological factors which were operative in the production of that syndrome in the cases described. It may sometimes be difficult to trace the psychogenic factors in non-psychotic patients though the very coarse nature of that conversion symptom makes it unlikely that the underlying psychological mechanisms would remain completely hidden in the unconscious. ${ }^{*}$

\section{Conclusions}

Two cases of spurious pregnancy occurring in women after the end of the reproductive period have been described. In both cases the idea of pregnancy formed the dominant content of thought in a

* An interesting historic example of spurious pregnancy occurring towards the end of the reproductive period in a non-psychotic woman was Mary, Queen of England (1553-1557), the daughter of Henry VIII; was Mary, Queen of England (1) overwhelming environmental influences during childin her case, the overwhelming adult life, cooperating in the origin of the syndrome can be easily traced (vide J. E. Neale, Queen Elizabeth, London, 1934). 
psychosis which in the first case was of the involutional melancholic, in the second case of the paranoid type. The prepsychotic personalities were characterized by psychosexual immaturity and there were histories of stillbirth and miscarriages which had acted as severe mental traumata. A variety of environmental factors predisposing to the formation of the idea of pregnancy could be demonstrated. The first patient had had a depressive mental reaction of the melancholic type following stillbirth. In that case physical signs and hormonal reactions suggestive of pregnancy were present for some time; in the second case physical signs were only abortive.

Spurious pregnancy has to be regarded as a psycho-somatic syndrome, the completeness of which depends on a variety of factors, the most important being the condition of the reproductive system and the extent to which the idea takes possession of the whole personality. It has been pointed out that the previous histories of the two cases described had much in common with those found in women who develop abnormal mental reactions following childbirth. It has been suggested that the syndrome of spurious pregnancy occurring after the end of the reproductive period should be studied in the context of the whole group of mental changes associated with the functions of the reproductive system, including hypochondriacal conditions following the menopause.

I wish to thank Professor D. K. Henderson for his advice in the preparation of this paper.

\section{REFERENCES}

Jacobs, B. (1943). J. ment. Sci., 89, 242.

Kehrer, E. (1928). Handb. Biol. Path. Weibes, WeinLeipzig ; 6, 714.

Maranon, G. (1929). The Climacteric. London.

Montgomery, W. F. (1857). The Signs and Symptoms of Pregnancy, Blanchard and Lea, Philadelphia (quoted by Paddock).

Moulton, R. (1942). Psychomat. Med., 4, 376.

Paddock, R. (1928). Amer. J. Obstet. Gynaec., 16, 845.

Schwarz, O. H. (1933). Obstetrics and Gynocology. London and Philadelphia. (Ed. by A. H. Curtis.) 1,675 .

Simpson, J. Y. (1863). Diseases of Women. Blanchard and Lea, Philadelphia, (quoted by Paddock).

Zilboorg, G. (1931). Amer. J. Psychiat., 10, 927. 